\title{
Developing efficient practices for producing bioethanol from sweet sorghum, evaluating several varieties of the plant and growing environments
}

\author{
Florin Nenciu ${ }^{1, *}$, Valentin Vlădut ${ }^{1}$, Gabriel $\mathrm{Nae}^{1}$, Lorena-Diana Popa $^{2}$, and Oana Emilia \\ Constantin ${ }^{3}$ \\ ${ }^{1}$ INMA Bucharest, Testing Department, Ion Ionescu de la Brad Blv. No. 6, Bucharest, Romania \\ ${ }^{2}$ University of Craiova, Faculty of Horticulture, Craiova, Dolj, Romania \\ ${ }^{3}$ University Dunărea de Jos, Galați, Faculty of Food Science and Engineering, Galați, Romania
}

\begin{abstract}
The challenges we face today envisaging environmental protection, starting from global warming and climate change, up to natural resources depletion, creates opportunities for developing new technologies for biofuel production. Considering that most biofuels used at the moment are based on energy-intensive crops, the question arises whether occupying large areas of land to the detriment of food is justified or not, especially as these crops generally deplete the soil of nutrients. In the present paper we propose a different approach for assessing an easily adaptable energy plant named Sweet Sorghum, that can grow with low input requirements, in difficult growing conditions, on contaminated or poor-nutrient and dry soils, and yet having a high productivity potential. Our research directions are targeted towards identifying the best opportunities for producing bioethanol from Sweet sorghum testing different varieties and sustainable planting conditions. We have been established several experimental cultures and evaluated the potential for producing biofuels using different techniques, such as juice extraction and fermentation and lignocellulose processing.
\end{abstract}

\section{Introduction}

There have been made important advancements towards reducing dependence on fossil fuels, both through several policies that encourage electric vehicles sale, but also by increasing the production and consumption of biofuels. A new challenge now is to reduce the fertile land area that is being cultivated with energy-intensive crops to the detriment of food and to increase the efficiency of biofuel production technologies.

A plant that is not yet used to its full potential is Sweet sorghum, which has excellent characteristics of adaptation and growth and high potential for producing bioethanol, using both first and second-generation technologies. In addition, this technical plant outperforms other similar cultures as an attractive climate-resilient crop in terms of reducing greenhouse

${ }^{*}$ Corresponding author: florin nenciu2000@yahoo.com 
gas emissions, being less demanding in agricultural work and having a high resistance to drought [1]. Various management practices may be used to reduce GHG emissions from the agricultural sector, the most promising being cultivation of crops with a higher potential for carbon sequestration ( $\mathrm{C} 4$ photosynthesis cycle crops), improve fertilization management, implementation of organic fertilizers and alternative soil amendments to replace synthetic fertilizers, precision farming, etc. [2].

Although many farmers consider sugar cane a much more effective plant for ethanol production, a large number of recent studies are demonstrating than Sweet sorghum has many additional strengths, in addition to the productivity factor [1]. Sweet sorghum is an extremely versatile plant that can be used successfully in the food industry for extracting natural sweeteners, or as animal feed, given the increased nutritional value of the vegetal part of the plant.

In terms of energy production, first generation bioethanol can be produced by direct fermentation using its juice, and second-generation bioethanol made from bagasse and seeds. From the vegetable mass can obtain biogas by anaerobic digestion, cogeneration of power by incineration of dried plants, or by applying various composting techniques may produce high quality fertilizers [2].

Other financially advantageous uses may also include roofing, paper production, or obtaining several chemical products. The multitude of possible uses gives farmers flexibility and the opportunity to comply with some stringent legislative provisions related to food versus fuel conflict, since they can produce simultaneously biofuels, edibles, or animal feed.

The sugars found in Sweet sorghum juice are a combination of sucrose, glucose, and fructose, with proportions varying by each plant genotype [3], this feature being an advantage over other possible sources that use carbohydrates to produce alcohol.

Sweet sorghum has a highly efficient photosynthetic system (C4), it is very efficient in the utilization of soil nutrients, even from lands depleted in nutrients and is resistant to pests without treatments.

Sweet sorghum offers the opportunity to establish two crops per year. Two annual crops involve an extended vegetation interval, therefore plants have to benefit of very good adaptation qualities to various environmental conditions, such as temperature, precipitations, seasonal diseases, or other soil properties variations that may occur over the year. These qualities have been studied in several papers that validate the high level of adaptability, tolerance to various abiotic stresses [4], or higher water, nitrogen, and radiation use efficiencies. The low need for irrigation is an important advantage compared to sugar cane, given that we expect in the coming years to be imposed several restrictions on the use of potable water in agriculture.

Second generation lingo-cellulosic ethanol production have developed rapidly in recent years due to the evolution of biocatalysts, such as genetically engineered enzymes, yeasts and bacteria. The processes allow producing ethanol from ligno-cellulose biomass including from cereal crop residues.

Some research studies show that producing biofuels from plants can bring harm to the ecosystem, since the leaves, stems and roots might be used for land conditioning [5]. The process involves letting the dried stalks and leaves of a cereal crop after the grain has been harvested, improving soil quality and sequestering carbon. Therefore, a strategy must be developed to produce as much bioethanol from lignocellulose, but without adversely affecting the soil properties. 


\section{Materials and methods}

Replacement of fossil fuels with biofuels brings improvements not only in terms of absorption of greenhouse gases by the plants during growth, but also positive phenomena is associated to combustion processes. Biofuels develop chemical reactions during combustion that cause polluting gases to be generated in much smaller quantities. Koppen et al., [6] evaluated the equivalent of GHG emissions saved from sweet sorghum cultivation, resulting between 1.4 and $22 \mathrm{~kg}$ per hectare emission reduction depending on yields, production methods, and the land cover. The assessment is important to highlight the better impact of reducing greenhouse gases by planting sweet sorghum compared to other similar crops or energy crops.

In addition to the environmental benefits, another considered aspect is the total energy gained from Sweet sorghum, since it is very important that the total energy consumed to produce the biofuel must be lower than the energy gained by bioethanol use.

This is not an easy task, because the agricultural works may have many variables related to the area, climate and soil. We have varied for each of the four pilot crops established, several agricultural works as sowing, pest control, irrigation, harvesting and processing.

According to United States Department of Agriculture (USDA) Sweet sorghum ethanol could produce between 12-16 Btu (British thermal units), for every Btu of fossil energy used in production.

Ethanol is produced from Sweet sorghum juice through direct fermentation technologies, from lignocellulose mass by processes of decomposition of vegetable mass into sugars, or by processing seeds, similar to other grains.

Productivity of Sweet sorghum crops may vary widely depending on the region, climate, crop management systems, yield, genotypes, efficiency of juice extraction and the manner fermentation is performed. Therefore, we can make some evaluations comparing to other similar energy crops, analyzing main benefits and weakness.

Our theoretical studies have shown that in order to obtain an increased efficiency, there must be an extraction rate of at least $35 \%$ from the clean stalks, while the bagasse can be used as animal feed, to be pelletized and burned for heat, or to produce electric power. However, the source of energy production and cattle for feeding should be in the vicinity of the crop, otherwise transportation costs can reduce efficiency to zero.

Sweet sorghum reaches maturity much faster than other plants such as sugarcane, requiring less water for development and has a higher fermentable sugar, therefore is better suited for ethanol production.

Sweet sorghum is a multi-functional culture, managing to generate products associated with the food industry (syrup, sugars), animal feed, bulk organic chemicals, industrial alcohol, restoration of soil quality and energy.

The main advantage Sweet sorghum has compared to other energy plants consist in maintaining high productivity without negatively affecting food production, since it can be cultivated on less fertile soils, in marginal lands or semi-arid regions, being a drought tolerant crop. The characteristic of having shorter growth duration allows establishing up to two crops per year, requiring low water and fertilizer input for development.

Hallam et. all. [7] evaluated the biomass production on both fertile and marginal lands and the annual expenses incurred with several annual Sorghum species in terms of biomass production compared to other crops. Have been showed that Sorghum had superior qualities compared to other annual and perennial plants that have been analyzed.

Sweet sorghum is considered an efficient method for nitrogen fertilizer of depleted soils [8]. Stevens et. all. [9] registered improvements in soil fertilization following planting of Sweet sorghum, when applying some methods of crop management, involving letting some of the bagasse or leaves on the field. 
Another aspect that have been studied was carbon sequestration in the soil layers using several sustainable land management practices, that allow to simultaneously improve soil quality and capture carbon dioxide. Sequestration of atmospheric carbon dioxide as organic carbon in the biosphere attracts attention as an alternate way to reduce the rates of greenhouse gases growth. Soil carbon sequestration is the process by which some plants with abundant development of the vegetal mass take the atmospheric carbon dioxide and store it into their biomass and land $[10,11]$.

Technical and economic analyses conducted by Farrell et al. [12] have shown that producing biofuels from lignocelluloses is projected to have the smallest contribution to the emission of CO2 and the largest net energy production, reaching up to quantities of 194001 per hectare, when is used the entirely biomass of the plants and when applying several efficient pre-treatment techniques. Considering the negative effects when using the entire mass of plants, a compromise solution could be partial exploitation of the plant mass for producing energy $[13,14]$. If only the stems and tips are used to produce bioethanol, while the leaves are left on the soil as a mulching surface, this practice could generate positive effects on the quality of agricultural land. The remaining leaves and roots are contributing to the sequestration of carbon in the soil, will transform into nutrients by decomposition, and help in fighting weeds. The constraints for large scale cultivation are the limited availability of genotypes suited for different agroclimatic conditions with all built-in resistances for biotic and abiotic stresses, photoperiod sensitivity and non-availability of required quantity of feedstock suited to off-season crushing in sugar industries $[15,16]$.

There are several ways of sequestrating carbon into the soil layers, either by rotating cultures, mulching or incorporating residues into the soil layers.

The study will further analyze aspects related to the production of bioethanol from 4 varieties of Sweet Sorghum crops, considering all the positive effects the crop may have on the environment. The experimental research approached the following main phases:

- Establish 4 Sweet Sorghum crops, on different soil types and in different climatic areas. Analyze growth and development for the four plant varieties

- Evaluate the potential of producing vegetal mass and quantify the percentage of each plant part: Leaves, plant tips with seeds, cleaned stems.

- Evaluate the techniques and equipment for processing sweet sorghum strains, in order to obtain juice.

- Fermentation and distillation of the juice, obtained by crushing sweet sorghum strains, highlight the maximum amounts of bioethanol that can be obtained from juice.

- Theoretical evaluation of the quantity of alcohol obtained by processing the vegetal mass in order to produce alcohol (by processing seeds and bagasse).

- Evaluating the levels of carbon sequestration in the land, by integrating sorghum leaves in soil layers.

\section{Results and discussion}

The experimental study was conducted during the period 2018-2020, and aimed on testing several Sugar sorghum species, that were established on soils having different characteristics, and in various geographical areas. Depending on the specificities of each area, have been applied different agricultural works, in order to optimize the production of vegetal mass. In case of the fourth crop, only minimal works have been performed, for testing sweet sorghum yields when adopting a management strategy that aims at minimum costs.

Four sweet sorghum varieties have been planted in experimental crops and analyzed over long periods of time. The agricultural lands were previously planted with wheat and corn crops (the soil had an efficient crop management in previous years), while for the 
establishment of culture, the soil have been ploughed and harrowed, nutrients have been added to bring it as close as possible to the optimal growth of sorghum. The planting operations were performed keeping a distance of $15 \mathrm{~cm}$ between plants and $60 \mathrm{~cm}$ between rows. Weed growth was controlled by mechanical weeding and an insecticide treatment was applied for pest control. Harvesting of sweet sorghum have been performed using an automatic threshing equipment, which cuts the stem from $2 \mathrm{~cm}$ above the ground, when the plant has reached maturity, and when the Brix index has exceeded the value of 19 Brix degree.

The equipment has a juice storage tank that can either be attached to a pump for driving the juice into a larger tank, or can accumulate the juice until filling.

The equipment is designed with three adjustable rollers, for a more efficient pressing of the stems. The mechanical part is driven by a motor that has adjustable speed, to customize the working advancement, depending on the operator number.
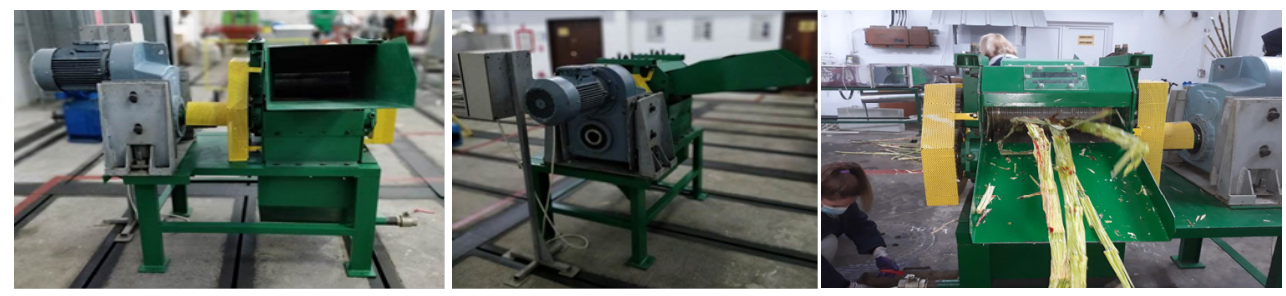

Fig. 1. Equipment for pressing sorghum stems to obtain bioethanol

The stems were cleaned of leaves and tips and transported to the laboratory, for further processing. In order to sequester carbon in the soil, the leaves were placed on the ground, forming a mulching layer. In this way, the decomposition of leaf mass will provide nutrients for next year's crop, and weeds will be more easily controlled. The plant tops and seeds were not left on the ground, in order to avoid germination in the following year.

The moisture level of the stems was determined using a hood and the Brix index was determined with an electronic refractometer.

Evaluations of the plant mass are also effective indicators for estimating the potential of sorghum plants, to be used as animal feed, the potential for sequestering carbon in the soil by integrating leaves into the soil layers, seed productivity for producing sorghum flour, or for assessing plants growth on different soils types.

The total amount of sugars and the mass of the plants may vary depending on the variety and on the harvest period, therefore it is essential to choose for planting the Sweet sorghum types that are able to develop vigorous stems and high amounts of sugars, but are also suitable to adapt to various soils and climatic conditions.

Table 1. Centralization of the main characteristics of four varieties of Sweet sorghum, planted in different climatic conditions 


\begin{tabular}{|c|c|c|c|c|c|c|c|c|c|}
\hline & & \multicolumn{8}{|c|}{ Sweet Sorghum plantations } \\
\hline & & \multicolumn{2}{|c|}{ Variety 1} & \multicolumn{2}{|c|}{ Variety 2} & \multicolumn{2}{|c|}{ Variety 3} & \multicolumn{2}{|c|}{ Variety 4} \\
\hline \multirow{3}{*}{ Plant characteristics } & $\begin{array}{l}\text { Number of sugar sorghum plants, } \\
\text { per square meter }\end{array}$ & $17-20$ & $\begin{array}{l}\text { plants per } \\
\text { square meter }\end{array}$ & $18-21$ & $\begin{array}{l}\text { plants per } \\
\text { square } \\
\text { meter }\end{array}$ & $19-21$ & \begin{tabular}{|c|}
$\begin{array}{c}\text { plants per } \\
\text { square } \\
\text { meter }\end{array}$ \\
\end{tabular} & $18-20$ & $\begin{array}{l}\text { plants per } \\
\text { square } \\
\text { meter }\end{array}$ \\
\hline & Average diameter of plants & 17.76 & $m m$ & 17.75 & $\mathrm{~mm}$ & 18.11 & $\mathrm{~mm}$ & 16.72 & $m m$ \\
\hline & \begin{tabular}{|l|} 
Average plant height \\
\end{tabular} & 2.6 & $m$ & 2.9 & $m$ & 3.2 & $m$ & 1.7 & $m$ \\
\hline \multirow{6}{*}{$\begin{array}{l}\text { Quantities obtained per } \\
\text { hectare }\end{array}$} & $\begin{array}{l}\text { Total plants mass harvested per } \\
\text { hectare }\end{array}$ & 72.26 & $t / h a$ & 78.1 & $t / h a$ & 86.2 & $t / h a$ & 51.2 & $t / h a$ \\
\hline & \begin{tabular}{|l|} 
Plant top with seeds \\
\end{tabular} & 4.46 & $t / h a$ & 4.44 & $t / h a$ & 5.72 & $t / h a$ & 5.8 & $t / h a$ \\
\hline & $\begin{array}{l}\begin{array}{l}\text { Stem mass } \\
\text { after removal of leaves and tips }\end{array} \\
\end{array}$ & 54.68 & $t / h a$ & 56.24 & $t / h a$ & 59.8 & $t / h a$ & 35.8 & $t / h a$ \\
\hline & \begin{tabular}{|l|} 
Bagasse \\
\end{tabular} & 38.28 & $t / h a$ & 38.6 & $t / h a$ & 38.87 & $t / h a$ & 29.46 & $t / h a$ \\
\hline & \begin{tabular}{|l|} 
Sorghum Juice produced \\
\end{tabular} & 16.4 & $k 1 / h a$ & 17.64 & $k l / h a$ & 20.93 & $k 1 / h a$ & 6.146 & $k 1 / h a$ \\
\hline & Seed mass & 1.09 & $t / h a$ & 1.13 & $t / h a$ & 1.21 & $t / h a$ & 0.71 & $t / h a$ \\
\hline Juice and bagasse analysis & Averege Brix & 19 & Brix degree & 18 & Brix degree & 19 & Brix degree & 19 & \begin{tabular}{|l|} 
Brix degree \\
\end{tabular} \\
\hline \multirow{3}{*}{ Percentages calculation } & \begin{tabular}{|l} 
Leaves \\
\end{tabular} & $18 \%$ & $\%$ & $24 \%$ & $\%$ & $23 \%$ & $\%$ & $19 \%$ & $\%$ \\
\hline & $\begin{array}{l}\text { Percentage of juice raported to the } \\
\text { processed stems (without leaves, } \\
\text { tips and signs) }\end{array}$ & $30 \%$ & $\%$ & $31 \%$ & $\%$ & $35 \%$ & $\%$ & $17 \%$ & $\%$ \\
\hline & $\begin{array}{l}\text { Percentage of bagasse, raported to } \\
\text { the processed stems (without } \\
\text { leaves, tips and signs) }\end{array}$ & $70 \%$ & $\%$ & $69 \%$ & $\%$ & $65 \%$ & $\%$ & $82 \%$ & $\%$ \\
\hline \multirow{3}{*}{ Alcohol production } & $\begin{array}{l}\text { Fist generation biofuels potential } \\
\text { (Juice fermentation) }\end{array}$ & 1.31 & $t / h a$ & 1.41 & $t / h a$ & 1.67 & $t / h a$ & 0.49 & $t / h a$ \\
\hline & $\begin{array}{l}\text { Second generation biofuels } \\
\text { potential (from bagasse) }\end{array}$ & 0.96 & $t / h a$ & 0.97 & $t / h a$ & 0.97 & $t / h a$ & 0.74 & $t / h a$ \\
\hline & $\begin{array}{l}\text { Biofuel generation by seeds } \\
\text { processing }\end{array}$ & 0.43 & $t / h a$ & 0.45 & $t / h a$ & 0.48 & $t / h a$ & 0.28 & $t / h a$ \\
\hline $\begin{array}{l}\text { Quantifying carbon } \\
\text { sechestration impact }\end{array}$ & $\begin{array}{l}\text { Carbon sechestration by burying } \\
\text { the leaves in the ground and } \\
\text { optimizing agricultural works }\end{array}$ & 0.42 & $\begin{array}{c}\text { tones } \mathrm{CO} 2 \\
\text { abatement rates } \\
\text { estimated per } \\
\text { ha per year }\end{array}$ & 0.48 & \begin{tabular}{|c|} 
tones $\mathrm{CO} 2$ \\
abatement \\
rates \\
estimated \\
per ha per \\
year \\
\end{tabular} & 0.47 & $\begin{array}{c}\text { tones } \mathrm{CO} 2 \\
\text { abatement } \\
\text { rates } \\
\text { estimated } \\
\text { per ha per } \\
\text { year }\end{array}$ & 0.43 & $\begin{array}{c}\text { tones } \mathrm{CO} 2 \\
\text { abatement } \\
\text { rates } \\
\text { estimated } \\
\text { per ha per } \\
\text { year }\end{array}$ \\
\hline
\end{tabular}

Figure 2 shows the percentages of each part of the plant, after processing (juice, top with seeds, bagasse and leaves), for each variety of Sweet sorghum.

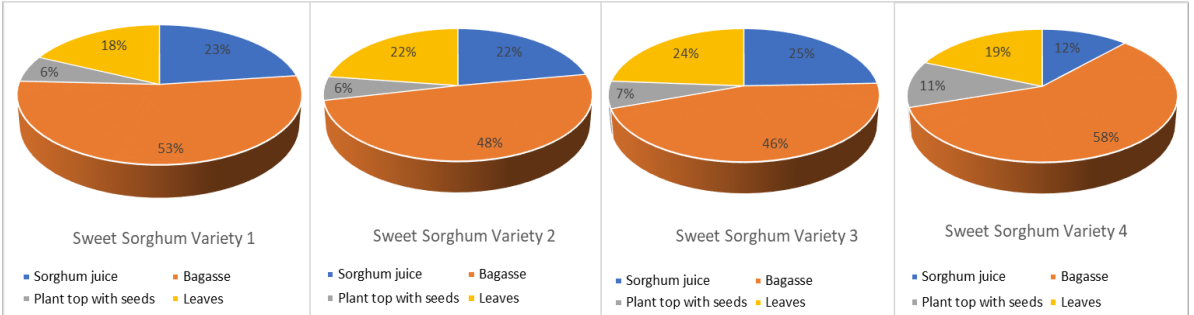

Fig. 2. Percentage evaluation of the main products obtained (juice, top with seeds, bagasse and leaves) after processing Sweet sorghum plants

If biofuel is obtained only by processing the juice, then a superior performance is observed for the crops that are benefiting from the best agricultural works, including irrigation. Variety 4, which had the least works performed, produced only $12 \%$ of the total plant mass (meaning $17 \%$ of the mass of cleaned stems), while variety 3 produced $25 \%$ of the total plant mass (meaning $35 \%$ of the mass of cleaned stems). The other varieties did not have significant variations of the 4 analyzed parameters.

If the biofuel is produced by processing the lignocellulosic mass, then we can evaluate the production per hectare for the 4 varieties, as can be seen in figure 3 . 


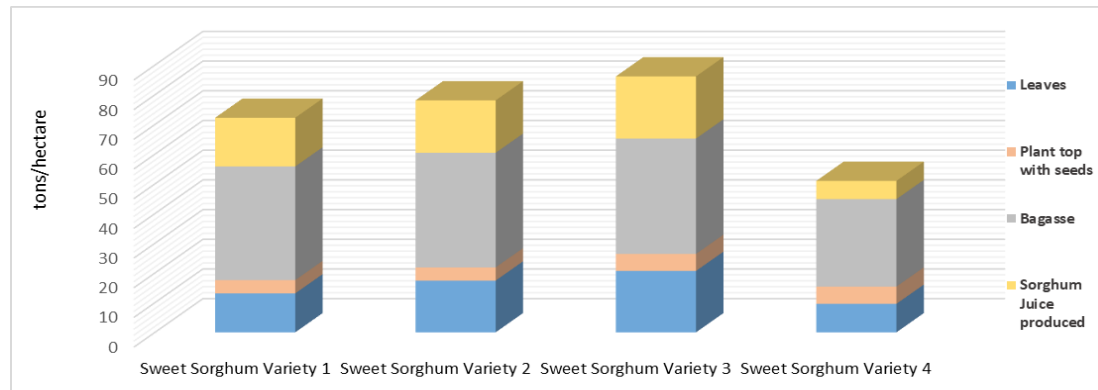

Fig. 3. Biomass expressed according to the main categories of products after processing: leaves, tops with seeds, bagasse and juice

Analyzing the amount of biomass obtained per hectare for several varieties of sugar sorghum in different cultivation areas and considering different agricultural activities applied to crops, can be seen that the quantities may vary significantly. It is therefore necessary to identify the best varieties adapted to local soil and climate conditions, in order to obtain maximum bioethanol production. Figure 4 shows the amount of juice and seeds obtained annually per hectare, in relation to the total biomass. The considerable difference between the total value of the plant mass and the juice and seeds shows the high opportunity to produce alcohol from the vegetable mass.

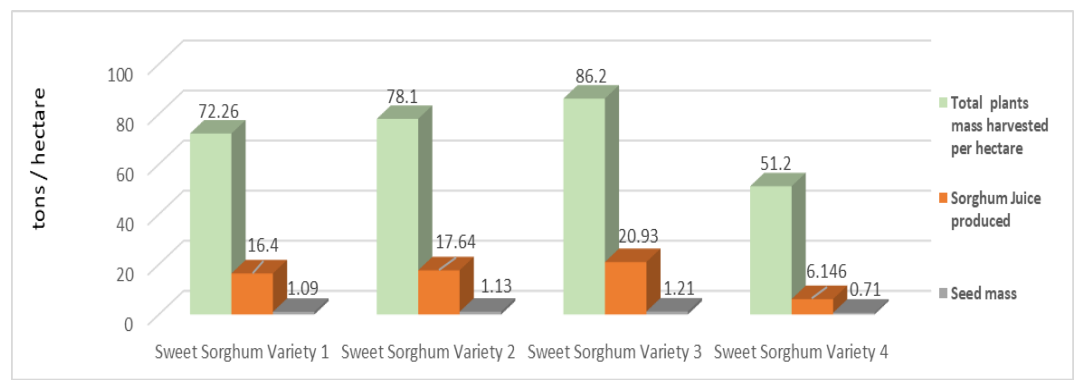

Fig. 4. Amount of juice and seeds obtained annually per hectare, in relation to the total biomass for Sweet sorghum crops

Although the vegetal mass is found in a much higher extent, due to the technological limitations, the maximum amount of bioethanol that can be obtained from bagasse remains relatively low, as can be seen in figure 5 .

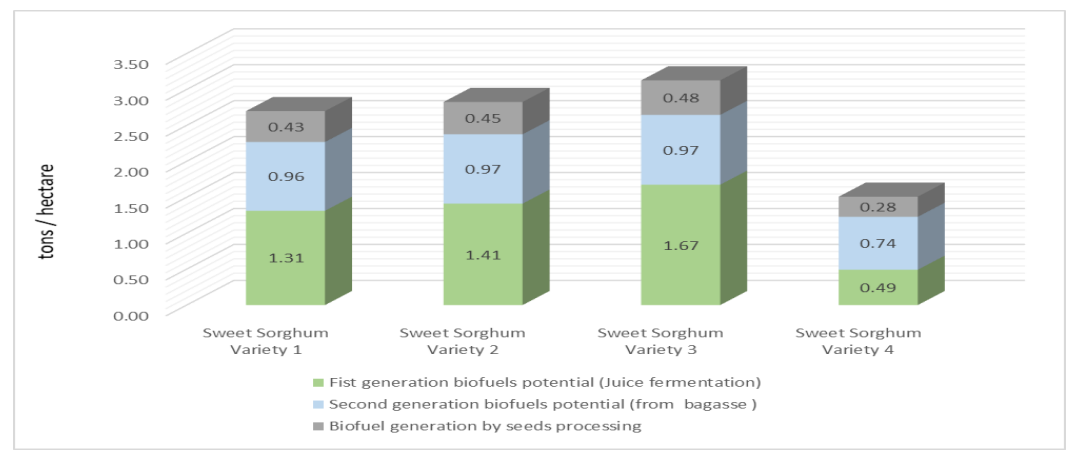

Fig. 5. Evaluation of the maximum amounts of bioethanol that can be obtained from each part of the Sweet sorghum plant 
Soil carbon sequestration is the process that allow to atmospheric carbon dioxide to be taken up by plants through photosynthesis and to be stored as stable carbon in biomass and soils. In addition to reducing air pollution, the process also helps in supplementing the carbon lost from the soil layers by adding a new amount of organic carbon. We tried to adopt a crop management that balances the efficient production of biofuels with protecting the health of the biosystem, by introducing some of the biomass in the soil. In this way, we were able to contribute to the increase of the nutrient content and to sequester carbon in the soil.

Sustainable land management practices lead to a decrease in the maximum potential for the use of biomass in the production of bioethanol, in favor of maintaining or improving soil quality. Eliminating only the leaves on the field, they will behave as mulch for next year controlling weeds, and as fertilizer when decomposing. In Figure 8 can be seen the estimated amounts of carbon that will be sequestered in the soil due to sustainable land management practices that have been applied, involving incorporating leaf residues and optimizing agricultural works.

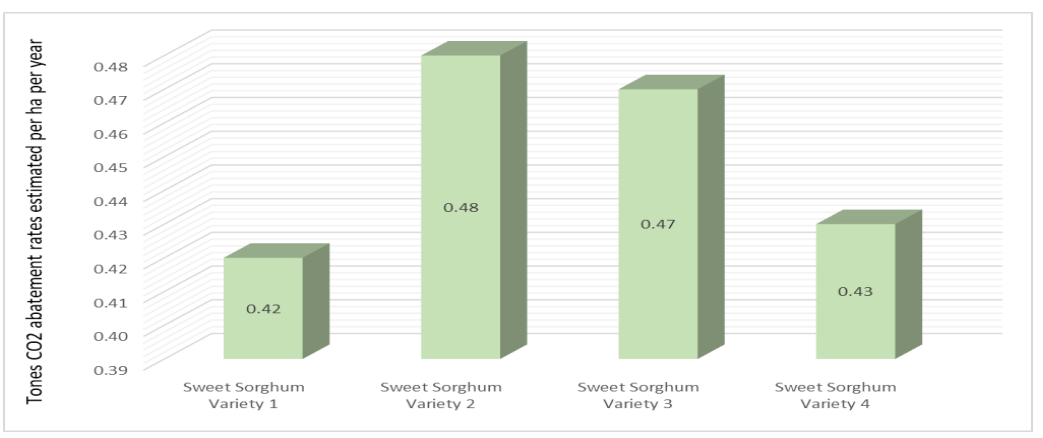

Fig. 6. Annual estimations of carbon sequestration in the soil when incorporating leaf residues and optimizing agricultural works for the Sweet Sorghum varieties

The application of the bagasse on the soil after the juice extraction was not considered, even if this option would have improved carbon sequestration values, considering the very high transportation costs.

\section{Conclusions}

In order to further reduce fossil fuels global use, we must simultaneously develop new processing technologies that will allow producing biofuels from juice extracts, lignocellulosic waste and seeds. In addition, we have to grow new varieties of plants adapted to severe climatic conditions and various soil characteristics that can be planted on marginal or depleted soils.

Have been showed that Sweet sorghum is a versatile crop, that has a high potential to produce ethanol from different parts of the plants, using different technologies, and due to its adaptability and resistance to extreme drought conditions, can be planted on marginal, polluted, nutrient-free or floodable soils.

Sweet sorghum is a promising solution to the food-versus-fuel debate, maintaining high ethanol productivity without negatively affecting food production. This approach leads to a sustainable crop management that protects and improves soil quality.

The characteristic of having shorter development duration allows establishing up to two crops per year, requiring relative low water and fertilizer input for development. However, 
has been shown that in the case of bioethanol production from fermentable juice, irrigation has a major impact in improving the efficiency of alcohol production.

We consider that future research should focus on new techniques and new genetic resources that could enhance productivity, improving stress tolerance characteristics, for crops that have a less impact on food supplies and on natural environment.

When using the bagasse for animal feeding or in direct combustion for producing energy, the farm or the power plant should be located in the vicinity of the plantation, or else there is a high possibility these activities generate higher costs than benefits.

The major challenges to biofuel technology from Sweet sorghum are the rapid degradation of the juice, high labor requirements, seasonality of the crop and the difficult process of turning lignocellulose into sugars.

This work was supported by a grant of the Romanian Ministery of Research and Innovation CCDI UEFISCDI, project number PN-III-P1-1.2-PCCDI-2017-0566, Contract no. 9PCCDI/2018, and PNCDI III, contract no. 16PFE

\section{References}

1. C.S. Wortmann, A. Liska, R.B. Ferguson, D.J. Lyon, R. Klein, I. Dweikat,. Agron. J., 102, 319-326 (2010)

2. M. Molaverdi, K. Karimi, M. Khanahmadi, A. Goshadrou, Ind. Crops Prod., 49, 580585. (2013)

3. A.V., Umakanth, A. Kumar, W., Vermerris, V.A., Tonapi, Breeding Sorghum for Diverse End Uses. Sweet Sorghum for Biofuel Industry, Chapter 16, Elsevier, 255-269. (2019)

4. T.T., Tesso, L.E., Claflin, M.R., Tuinstra, (2005). Analysis of stalk rot resistance and genetic diversity among drought tolerant sorghum genotypes. Crop Sci., 45, 645-652

5. B.V.S., Reddy, S., Ramesh, A.A., Kumar, S.P., Wani, O. H., Ceballos, T.K., Sreedevi,. Bioenergy Res. 1, 248-258, (2008)

6. S. Koppen, G. Reinhardt, S. Gartner,. Assessment of Energy and Greenhouse Gas Inventories of Sweet Sorghum for First and Second Generation Bioethanol, 77, (2009)

7. A. Hallam, I.C. Anderson, D.R. Buxton, Biomass and Bioenergy, 21, 404-424, (2001)

8. M. Bitzer,. Research report: Early deheading of sweet sorghum. National Sweet Sorghum Producers and Processors Association. http://nssppa.org/, (2009)

9. G. Stevens, R. Holou, D. Dunn, A. Wrather. Switchgrass and sweet sorghum fertilization for bioenergy feedstocks. Proc. Southern Plant Nutrition Management Conf., MS, 38-45, (2009)

10. A.C. Abdullahi, C. Siwar, M.I. Shaharudin, I. Anizan. Intechopen, Carbon Capture, Utilization and Sequestration, (2018)

11. A., Almodares, M.R., Hadi, Afr. J. Agric. Res. 4, 9, 772-780; (2009)

12. A.E. Farrell, R.J. Plevin, A.D. Turner, M. Jones, D.M. O'Hare Kammen. Science 311 (5760), 506-508. (2006)

13. M.O. Oyier, J.O. Owuoche, M.E. Oyoo, E. Cheruiyot, B. Mulianga, J. Rono. The Scientific World Journal., 1-10, (2017)

14. S.R. Pinnamaneni, U. Akula, N. Seetharama, S.S. Rao, The Internat. Crops Research Inst. for the Semi-Arid Tropics (ICRISAT), 1-71. (2009)

15. R. Silva e Souza, R.A. da Costa Parrella Vander, F. de Souza. N.N.L.D. Parrella Cienc. E Agrotecnol. 40, 46-56, (2016)

16. K.S. Vinutha, L. Rayaprolu, K. Yadagiri, A.V. Umakanth, P. Srinivasa Rao, Sugar Tech. 16 (2), 133-143; (2014). 